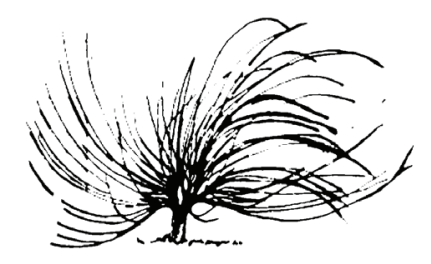

\title{
Determinaciones categoriales y noción conceptual de la educación: Una lectura crítica en torno al Sistema Interregional Indoeuropeo
}

\author{
Ernesto Herra Castro ${ }^{1}$ \\ Universidad Nacional \\ Heredia, Costa Rica \\ ernesto.herra.castro@una.cr
}

\begin{abstract}
Resumen
Este artículo intenta identificar diversos momentos educativos subsumidos en el conocimiento científico como uno de los muchos saberes humanos con miras a impulsar otros horizontes de sentido que fomenten la producción y reproducción de la vida comunitaria. Se identifican los aportes del saber indoeuropeo y las tensiones existentes a partir de la formalización de sus saberes por la racionalidad helena.
\end{abstract}

Palabras clave: sistema interregional indoeuropeo, filosofía, ciencia, educación, sabiduría, conocimiento, vida comunitaria.

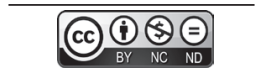

Recibido: 11 de julio de 2016-Aprobado: 3 de octubre de 2017

http://dx.doi.org/10.15359/rep.12-2.6

1 Docente e investigador de la Escuela de Sociología de la Universidad Nacional. Se desempeña, actualmente, como coordinador de la Red "Epistemologías del Sur: Red de pensamiento anticolonial respecto de lo migratorio, lo educativo y lo rural". 


\begin{abstract}
This article tries to identify different educational moments subsumed in scientific knowledge as one of the many manifestations of human knowledge with the purpose of boosting other kind of horizons of sense to encourage the production and reproduction of community life. It identifies the contributions of Indo-European knowledge and the existing tensions from the formalization of knowledge by Greek rationality.
\end{abstract}

Keywords: Indo-European interregional system, Philosophy, Science, education, wisdom, knowledge, community life.

\title{
Introducción
}

La educación, como institución medular de nuestra especie, está atravesada por dos momentos fundantes: el aprendizaje y la enseñanza. $\mathrm{Su}$ función ha tenido que ver con la posibilidad de nuestra especie de aprender de la realidad de la cual somos parte para garantizar así nuestra subsistencia.

El desarrollo de la lengua (idioma) y el lenguaje (interacciones en el marco de una o varias lenguas), que surgen con la aparición de nuestra especie (Echeverría, 2015), nos ha permitido enfrentarnos a los "núcleos problemáticos" (Dussel, 2015, p. 12) que nuestra capacidad de raciocinio ha impulsado producto del asombro de ver la vida como un milagro (Kusturica, 2004).

El despliegue del acervo lingüístico ha permitido la “...continuidad entre los procesos biológicos y las acciones - de nuestra especie-, cuyas coordinaciones constituirán el comienzo de lo que serán los procesos cognoscitivos, así como continuidad en los mecanismos cognoscitivos precientíficos y científicos" (García, 2000, p. 60). Lo anterior permitirá desarrollar las condiciones de sofisticación de las preguntas orientadoras, los mecanismos de constatación y el lenguaje con que en adelante la especie podrá obtener los mismos resultados ante la aplicación de los mismos procedimientos (Ciencia) (García, 2000; García, 2013).

El conocimiento, como método ligado a la producción científica, “...surge en un proceso de organización de las interacciones entre un sujeto ("el sujeto de conocimiento") y esa parte de la realidad constituida 
por los objetos ("el objeto de conocimiento")" (García, 2000, p. 61). Sin embargo, como ya hemos demostrado en trabajos anteriores (Herra y Navarro, 2015; Herra y Baraona, 2015a; Herra y Baraona, 2015b), el Sujeto en condición de hacer la política, la filosofía y la guerra está ligado a la organización social de un proyecto teológico, que gira en torno a aristócratas y oligarcas, a través de la producción y reproducción de los privilegios que en su inicio están acaparados por hombres, poseedores de recursos materiales, en capacidad de leer y escribir, atenienses, reconocidos socialmente como mayores de edad ${ }^{2}$ (Herra y Baraona, 2015a). Dado que el pensar es un proceder categorial (Bautista, 2011); que las categorías permiten establecer relaciones con otras categorías que se constituyen en las "partes del conocimiento sistemático científico" (Dussel, 2014a, p. 24) que indican un momento del concepto, "representación explícita" de alguna cosa que, "como su nombre lo indica es fruto de una concepción racional que refiere al contenido global y en movimiento (...) mientras que las categorías indican un momento del mismo concepto, constituidas por el entendimiento representativo (...) como instrumento de interpretación en el orden del concepto, de un sistema, de un plan, del discurso dialéctico. El concepto dice relación a la estructura total y dialécticamente móvil de las determinaciones; las categorías dicen relación a otras categorías" (Dussel, 2014a, pp. 23-24).

Lo que intentaré hacer en este breve trabajo es mostrar distintos "momentos educativos", que es como he llamado a las determinaciones categoriales propias del sistema ético indoeuropeo (desde el siglo XX a. C., en adelante), que dan forma constitutiva, aún en la actualidad, de lo que comprendemos racional y conceptualmente como educación. Se trata de identificar los momentos de quiebre que han tensado después la producción y reproducción de la vida en el planeta

2 En otro trabajo, por publicarse, que he denominado "Economía política de las categorías" he sugerido pensar la Modernización como la actualización continua de los mecanismos de Adaptación y Resistencia que se despliegan alrededor de la tierra solo posterior a la organización de un Sistema mundial que gira en torno a Europa desde 1492, Modernidad. La actualización de los mecanismos de Adaptación y Resistencia a la desigualdad Moderna, Sexista/ Racista/Clasista tiene un ethos masculino, mas en la actualidad ya no es representado solo por un cuerpo que es hombre; además de poseer recursos materiales, vive a costas del trabajo ajeno (Capitalista); no solo está en capacidad de leer y escribir, tiene estudios técnicos y/o científicos; la actual crisis económica que atraviesa Grecia ha dejado en evidencia que definitivamente no es ateniense, mas sí procede de la ciudad; su mayoría de edad consta de estar en condiciones de producir valor, lo que en la dinámica capitalista se traduce en producir valor para otro que vive a costa del trabajo ajeno. 
al punto de conducirnos hoy a “...un escenario de desintegración terminal llevándonos a la extinción, o al borde de ella" (Baraona y Herra, 2016, p. 273).

Se trata entonces de confrontar la "fe racional" que ha sustituido a la "fe teológica" en la que ser y verdad se constituyen en "... dos pilares fundamentales y mutuamente dependientes de la armazón metafísica" (Echeverría, 2015, p. 40), la cual está estructurada a partir de la relación Sujeto-predicado del griego, latín y lenguas romances, desarrollada mediante silogismos. La tradición filosófica helena logró dar fundamento racional a la escisión del ser humano (nomos) y la naturaleza (physis) dejando en evidencia que "nuestro lenguaje ordinario, alude a un juicio que realizamos sobre una determinada proposición lingüística que le atribuye a ésta la capacidad de dar cuenta de "cómo las cosas son"” (p. 40), aun cuando "no sabemos cómo las cosas son. Sólo sabemos cómo las observamos o cómo las interpretamos" (p. 40). De esta forma podemos afirmar, junto a Echeverría (2015), que la verdad es "la pretensión de que 'las cosas' son como decimos" (p. 40).

Dado que "el lenguaje es el sistema de la coordinación de acciones mantenida por una comunidad y, como tal, está enclavado en sus prácticas sociales, en la forma en que sus miembros interactúan entre ellos" (Echeverría, 2015, p. 58) y que la gramática social que nos atraviesa está conformada por relaciones de dominio que nos ubican, como pueblos del Tercer Mundo, en el lugar del objeto o del predicado, es que pretendemos identificar y proponer algunas de las determinaciones contenidas en la práctica educativa Moderna. Se trata de identificarlas para no solo confrontarlas, sino ir más allá que ellas y pensar "la educación como una forma de proteger a la gente para que no se deje educar" (Feyerabend, 1984, p.150).

\section{Conocimiento y sabiduría en la tradición helena}

La separación entre el conocimiento y la sabiduría forma parte de una jerarquización respecto del tipo de conocimiento Occidental y el no Occidental, denominado en Quijano (2000) como "Epistemología del poder". De lo que se trata es de impulsar un orden que gire en torno a un solo tipo de noción epistémica que posiciona, en un lugar de privilegio, los conocimientos, saberes, estéticas, credos, tradiciones culturales, etc., occidentales sobre los no occidentales. Entretanto el conocimiento 
es concebido como el producto del saber científico, la sabiduría es un principio humano mucho más amplio que abarca lo científico pero que no se limita a él. Mientras que el conocimiento es un tipo de sabiduría que ha sido formalizada e institucionalizada según los valores, juicios, prejuicios y subjetividades de aquellos pueblos que, desde la Grecia clásica (siglos IV y III a. C.), se han impuesto militar y racionalmente sobre otros; la sabiduría, por el contrario, reúne a los saberes múltiples y diversos que han hecho posible la producción y reproducción de la vida humana en la tierra.

A partir del siglo XX a. C., los pueblos procedentes del norte del Mar Negro, los Cáucasos y un amplísimo territorio comprendido entre Mongolia y el Mar Caspio, ya que la historia del pensamiento ético-filosófico nos permite identificar el desarrollo histórico del pensamiento humano así como los aportes que cada uno de ellos ha hecho en la sofisticación de éste nos indica que ha viajado del oeste hacia el este, impulsando la creación de la India, establecida en las orillas del río Indo desde el 2500 a. C., o China, en las orillas de los ríos Hoangho (río amarrillo) y Yangtze kiang (río Azul), desde el 2000 a. C. (Dussel, 2009, pp. 11-86; Asimov, 2011).

A diferencia del sistema interregional anterior, el egipcio-mesopotámico del que he dado cuenta en un trabajo anterior ${ }^{3}$, impulsado por un horizonte teológico dirigido por una multiplicidad y diversidad de dioses surgidos a partir de la creación del Universo por Ptah, quien al habernos dotado de razón, palabra y sabiduría (Thot), además del Sol, la Lluvia o la Noche, en el sistema interregional Indoeuropeo es "el fundamento, la Identidad de todas las Diferencias, la referencia última del mundo (cosmológico, antropológico, ético) es en estas cosmovisiones (y aun filosofías) la afirmación de un horizonte absoluto de lo real como lo 'Uno'” (Dussel, 2009, p. 32).

3 En un trabajo anterior he identificado distintos Momentos Educativos subsumidos en la formalización de la ciencia, llevada a cabo a partir del siglo VI a. C., en Grecia. En dicha formalización ha quedado reducida la Ciencia a un aparataje técnico que permite la reproducción de las condiciones de dominio y explotación que le posibilitarán "determinar" a sus múltiples "objetos". Lo que aquí quisiera mostrar es el origen de la tensión contenida en el devenir científico que gira en torno a la "Ciencia de Adquirir" por encima de la "Ciencia Doméstica" (Aristóteles, 2007). Es desde este último posicionamiento que intento hacer la lectura crítica propuesta en el intento de pensar a "Determinaciones abstractas y noción conceptual de la educación. Una lectura crítica a la acumulación del saber”. 
A lo largo y ancho del territorio comprendido en el Sistema Interregional Indoeuropeo ${ }^{4}$, se habían logrado domesticar animales no solo para el trabajo, sino también para la guerra. La tecnología bélica desarrollada hasta entonces les había llevado a dominar el bronce, primero, y posteriormente el hierro (Asimov, 2011).

Como sociedades nómadas y especializadas en la caza, principalmente, el desarrollo y perfeccionamiento de su tecnología militar era esencial para ampliar el dominio que estas ejercieron sobre los pueblos agricultores, ligados a la tierra concebida como madre (Dussel, 2009), mientras las relaciones de dominio impuesto sobre los pueblos agricultores eran respaldadas en la creencia en dioses uránicos, sobre todo masculinos.

Según Dussel (2009), el sistema interregional indoeuropeo logró aglutinar a los pueblos de la "Anatolia, del Nilo, del Éufrates y de Tigris, del río Indo y hasta el río Amarillo. Ellos organizaron los primeros grandes imperios, culturas o 'visiones de mundo' tales como las hindúes en India, persas en Irán, griegas y romanas en el Mediterráneo, budistas desde el Nepal, y, por influencia indirecta, taoísta y confuciana en la China" (p. 32).

Los pueblos organizados en estos vastos imperios habían desarrollado una impresionante maquinaria militar, terrestre y naval, que, entre otras cosas, les había permitido establecer relaciones comerciales con los pueblos originarios del Abya-Yala, mucho tiempo antes de lo que lo hicieran los europeos, como lo demuestra el gran conocimiento cartográfico que desde 1418 habían desarrollado los almirantes chinos, que permitía comprender la redondez de la tierra y lo que en ella había (Menzies, 2015).

El horizonte teológico dirigido hacia la nulidad de la diversidad, de la imposición de una única verdad como fuente absoluta de lo real (Dussel, 2009) los había llevado a comprender, como más tarde lo haría en la tradición cristiana San Agustín, al cuerpo como cárcel del alma (Hinkelammert, 2013, pp. 160-176), por lo que el cuerpo, donde se encierra la vida temporal, es el resultado de haber cometido una falta ética anterior al nacimiento a lo cual debe su nacimiento, mientras que la muerte física es interpretada como nacimiento a la vida eterna y a la

4 Este extenso y diverso territorio tiene como centro a la Región persa, al Mundo heleno (seléucida y ptolomaico) "desde el siglo IV a. C"; en el extremo oriental tiene a China; al sudoriental a los Reinos de la India; y el occidental al Mundo Mediterráneo (Dussel, 2009, p. 21). 
verdadera vida. De esta forma, la tierra, la mujer, la política, en fin, aquellos elementos femeninos que son los únicos en nuestro planeta en capacidad de producir la vida, deben ser dominados y controlados, lo que impulsa un tipo de organización social en capacidad ética ${ }^{5}$ de justificar las relaciones de opresión hacia la tierra, la mujer, la diversidad, la esclavitud, el servilismo que permiten la estructuración de un orden desigual que gira en torno al reconocimiento de privilegios de aristócratas y oligarcas (Herra y Baraona, 2015a).

Esta inferioridad del "Otro/Otra" tiene cabida solo en el marco de las relaciones sociales y no biológicas, físicas o intelectuales, pero debía ser en estos campos donde dicha inferiorización tendría sentido práctico real. Esto permite que la Grecia clásica (siglos IV y III a. C.) logre contar con una población en condiciones de esclavitud cercana al 70\% (Herra y Baraona, 2015a).

Dado que la liberación, concebida desde esta noción teológica de la opresión, es solo una posibilidad en la medida que se trascienda la prisión del cuerpo, el celibato masculino o la virginidad femenina juegan aquí un papel institucional fundamental, ya que la posibilidad de llevar una vida contemplativa, de cercanía con los dioses (mayor de los estadios al que podía aspirar la humanidad en el horizonte de sentido heleno (Dussel, 2009)), es solo posible cuando se cuenta con una vasta base de población en condiciones de producir valor para otro que vive a costas del trabajo ajeno. Es por ello que las víctimas, las y los pobres, las y los excluidos, las y los esclavos no son un problema o aparecen en el escenario problemático de este tipo de concepción ética del mundo.

La estructuración y organización social de un sistema basado en relaciones de privilegios/opresión a partir de un horizonte teológico constituye uno de los principales aportes del sistema interregional indoeuropeo a los sistemas éticos posteriores. Los pensadores helenos Platón (427-347 a. C) y Aristóteles (384-322 a. C.) reconocen, en distintos momentos de sus obras, a las comunidades de pensadores y sabios

5 Pensaremos la ética junto a Enrique Dussel (2009) como la consecuencia coherente de tener responsabilidad sobre sus actos. Debido a que "el lenguaje NO es una capacidad individual, sino un rasgo evolutivo que, basándose en condiciones biológicas específicas, surge de la interacción social" (Echeverría, 2015, p. 54), al mismo tiempo que "el lenguaje no sólo nos permite hablar "sobre" las cosas: el lenguaje hace que sucedan cosas. El lenguaje genera ser" (Echeverría, 2015, p. 33), es que comprendemos que cada sistema ético ha llegado a confrontarse con sus fundamentos éticos hasta generar las condiciones que han impulsado el surgimiento de un nuevo sistema ético. 
egipcios como la cuna de su pensamiento racional y ético (Dussel, 2009; Asimov, 2011).

Ante lo anterior me atrevo a señalar un Primer Momento Educativo del Sistema Interregional Indoeuropeo en que los saberes acumulados y perfeccionados por la humanidad desde nuestra aparición, hace alrededor de 130.000 años, hasta su formalización en la Grecia clásica (siglos IV y III a. C.), han quedado subsumidos e institucionalizados permitiéndole a la humanidad contar con el saber matemático para impulsar el control sobre una estructura cada vez más desigual y estratificada. A este momento educativo, que por primera vez ya no se organiza para hacer y reproducir la vida comunitaria, sino en producir y reproducir la desigualdad lo quisiera proponer, en tanto momento constitutivo de la dinámica educativa contenida en el proyecto de la Modernidad, como "Saber para el Dominio".

Se pone en marcha la reproducción de un orden político que tiende a privilegiar a oligarcas y aristócratas a través del control y la administración hegemónicos, como lo "Uno" (Dussel, 2009), del aparataje institucional del Estado. Este es el inicio de la reproducción del orden sexista/racista/clasista (Herra y Baraona, 2015a; Herra y Baraona, 2015b) que caracterizará a los sistemas éticos posteriores. De lo que se trata es de justificar racional y éticamente la "apropiación excluyente del excedente de la comunidad" (Dussel, 2014b).

Este "Saber para el Dominio" será incorporado y formalizado en el pensamiento heleno desde Tales, considerado como el primer filósofo griego hacia alrededor del 625 a. C., al ser el primero que impulsa una concepción y relacionamiento con el mundo a partir de la construcción de herramientas conceptuales que ya no solo permiten nombrar el mundo, sino contar con instrumentos de mediación interpretativa (Saavedra, 2013, p. 19) que, a partir de ahora, se constituyen en las herramientas con las que el Sujeto que piensa construye su objeto. Estas herramientas conceptuales, cuya sofisticación permite establecer una relación y medición de "la realidad", constituyen el mundo en el que se desarrolla la existencia del individuo y en el que uno y otro cobran sentido según los términos lingüísticos con los que el aprendizaje se abre al mundo exterior.

Ahora nos volvemos a arriesgar a equivocarnos y quisiéramos proponer, hasta aquí, la existencia de un Segundo Momento Educativo de este Sistema Ético caracterizado por la "Institucionalización Formal de un Saber para el Dominio". Lo proponemos de esta forma debido a 
que la reproducción de un orden basado en relaciones de privilegio/opresión, cuyos privilegios les permiten a Hombres, Atenienses, Poseedores de Recursos Materiales, en condiciones de Leer y Escribir, reconocidos socialmente como mayores de edad vivir a costas del trabajo ajeno.

La racionalización, formalización e institucionalización del sexismo/clasismo/racismo heleno privilegia lo masculino, lo citadino, lo escolarizado, lo bello, lo sano, lo adulto, etc., que tiende a reproducirse en la estructura del Estado (Herra y Baraona, 2015a), razón por la que la democracia o la filosofía helena se muestran como las únicas en posibilidad de construir criterio verdadero con alcance universal. Los dioses uránicos, de donde se nutre la noción teológica helena, son guerreros, razón por la que Aristóteles (2007) piensa al Estado como "comunidades de guerreros" que "sólo deben pensar en obedecer y no en intentar revoluciones" (Aristóteles, 2007, p. 44).

Lo anterior refleja que la tradición griega hacia lo "uno", lo único, la totalización que se logra al formalizar su proceder categorial es parte de una estructura geográfica y ética que lo vincula con Asia y no con Europa, al mismo tiempo que restringe lo diverso que es sólo posible mediante un horizonte ético impulsado por lo "uno" (Dussel, 2009).

El tipo de pregunta desarrollada e impulsada en la Grecia Clásica (siglos IV y III a. C.) está ubicada en un contexto de intensas confrontaciones bélicas en el que Atenas, Esparta y Macedonia se disputan el control del comercio marítimo que gira en torno al Mar Mediterráneo, en el cual Macedonia culminaría por imponerse y desplazar a Atenas del centro de las relaciones comerciales que alguna vez ocupara" (Herra y Baraona, 2015, p. 1).

Atenas volverá a ocupar un lugar de centralidad en la dinámica económica circunscrita en el Mar Mediterráneo una vez que Alejandro, quien había sido encargado bajo la tutela de Aristóteles desde el 343 a. C., hasta el año de su muerte en 323 a. C., haya destruido Tebas y conquiste Atenas (Pagden, 2014, pp. 27-39).

Lo anterior marca un momento clave en la dinámica educativa y es la Institucionalización Formal-Categorial de un Saber para el Dominio. Si bien, las escuelas de artes y oficios ya existían en Egipto o Mesopotamia, e incluso los sabios de las tierras anteriormente señaladas contaban con sus propios centros de formación, la institucionalización 
formal de este tipo de proceder racional tuvo primero a la academia, como institución que reprodujo el horizonte de sentido trazado por Macedonia en su momento de predominio sobre el Mar Mediterráneo, y, posterior a la toma de Tebas por Alejandro y al regreso de años de exilio de Aristóteles a su tierra, al Liceo (Aristóteles, 2007, pp. 5-9). Propongo este como el surgimiento del Tercer Momento Educativo del Sistema Interregional Indoeuropeo al que he denominado, según sus características, Momento de Escolarización para la Reproducción de un Saber para el Dominio.

\section{Conocimiento y sabiduría en la tradición romana}

A partir del siglo VI a. C., se desarrolla un proceso de organización de lo que en principio fueron tres $\mathrm{y}$, hacia el final, treinta y cinco pueblos, etruscos y griegos principalmente, que se asentaron sobre el valle del río Tíber y dieron impulso a la creación de la República de Roma (509-27 a. C.) (Asimov, 2011). La sumisión de las comunidades griegas ante las etruscas, durante los primeros siglos, así como el hecho de que en su época imperial (27 a.C.-476 d. C) Roma pensó en Grecia, le permitió a Roma erguir un complejo sistema social alrededor de una ciudad-estado que se extendió hasta su caída hacia el 476 de nuestra era (Imperio Romano de Occidente) y 1453 (Imperio Romano de Oriente) y que incluso se prolongará hasta 1789 (Revolución Francesa), año de su caída final.

El pueblo etrusco, quien se impuso en términos de organización sobre el griego, estaba organizado políticamente en una monarquía absoluta, la cual reconoce a su Rey como sumo sacerdote y jefe de las fuerzas armadas. Esta monarquía absoluta termina por convertirse en una dictadura militar hacia el siglo IV a. C., organizada oligárquicamente con la existencia de magistraturas y colegiaturas. Al contrario de las griegas, las mujeres etruscas formaban parte de la vida política y la aristocracia, por lo cual ocupaban el mayor escalafón dentro de la estructura socioeconómica trazada por su pueblo ${ }^{6}$.

La organización social del pueblo etrusco se dio en torno al agro, principalmente porque es la tierra el único lugar en el que el ser humano,

6 En la dinámica romana la aristocracia ocupaba la cima, seguida por el pueblo (el pueblo etrusco no aristócrata), los extranjeros y, por último, los esclavos. 
comprendido en su inmensidad/complejidad/diversidad, puede hallar alimento. No es casual, durante este período, el culto espiritual a imágenes de mujeres, las cuales provenían principalmente de Oriente y que la Iglesia occidental fue incorporando, en tiempos apostólicos, a la Hispania romana que ocupaba las provincias bética, cartaginesa, tarraconense, lucitana y galliciana, logrando extenderse por todos los territorios mediterráneos durante el siglo IV de nuestra era (Asimov, 2011).

El estoicismo, corriente filosófica que entró en Roma hacia el 150 a. C, es, quizá, la escuela neoplatónica y postaristotélica que experimentó el mayor auge y crecimiento en el pensamiento romano durante su conformación imperial. Su incorporación en el marco institucional romano no dejó de experimentar tensiones y resistencias al confrontarse con el absolutismo estatal y la esclavitud, superando así los sesgos clasistas, si se pudiera pensar algo semejante, de las posturas aristotélicas y platónicas de las cuales esta escuela se nutría (Saavedra, 2013, pp. 17-32). De esta forma, en términos prácticos, mientras que en el marco individual los ciudadanos romanos encontraban en el estoicismo la posibilidad de humanizarse, en la realidad seguía siendo la nobleza y aristocracia quienes ocupaban los aparatos de poder y control compartidos, ahora, con la naciente burguesía comercial, el papado y los distintos poderes de la Iglesia cristiana, la cual logró desarrollarse y expandirse teológicamente en tiempos de la "pax romana" a través de una compleja estructura legal, normas y leyes desprendidas de un código legal común. Hay que recordar que una vez que el Emperador Constantino I aceptó durante el siglo IV d. C., en su lecho de muerte, al cristianismo como su religión la Iglesia cristiana se convertirá en Iglesia del Imperio, Iglesia del poder: Cristiandad.

Pensamos que el surgimiento de un aparataje legal común, constituido alrededor de un código de derecho, conocido hasta la actualidad como "Derecho Romano", que permite la reproducción de un orden común a los intereses oligarcas, aristócratas y eclesiales, como un momento educativo clave que debe ser diferenciado de las formas de organización anteriores. Si bien la filosofía helena le permitió a Grecia tener un papel protagónico en lo sucesivo a su proyecto de dominio, el Derecho Romano lo es para Roma. Este, que es respuesta a la complejidad social que se desarrolló en Roma, es el resultado de la compilación de las "Doce Tablas" que constituyen la base legal que garantizaría el acuerdo y entendimiento común según las prácticas, los 
usos y las costumbres del pueblo romano (Asimov, 2011), de las cuales se desprenden leyes, normas, acuerdos que mediarían las relaciones sociales de esta ciudad. Paralelo al Derecho Romano fue necesario desarrollar las estructuras administrativas de las leyes, así como el sistema educativo que permitiera erguir y reproducir el Imperio. El emperador bizantino Justiniano (484-565 d. C.) impulsó el desarrollo de un único código legal, el cual fue reunido en cuatro grandes libros: el Código, el Digesto, el Pandectas y las Instituciones.

Ahora existe un solo Dios, una sola Ley, un solo modelo de sociedad en el Imperio común que consta de todo aquel territorio hasta donde Roma se ha expandido. Por lo anterior me gustaría proponer un Cuarto Momento Educativo como Momento de Institucionalización Formal de un Código Legal para el Control, la Reproducción del Poder y centralidad de Roma.

De esta forma inicia un largo período de la historia occidental caracterizado por el oscurantismo, pecado, celo por el poder, despotismo que tiene como fundamento la expansión del control, del dominio de la Iglesia cristiana en cada espacio del orden social. Este período es denominado Edad Media (siglos IV-XIV d. C.). De este modo, el poder del papado se impondrá como única fuente y criterio de verdad hasta que surja un tiempo nuevo, impulsado por nuevas preguntas que, en el caso de la Europa latino-germánica, tienen que ver con el acceso a los saberes, conocimientos y a la producción tecnológica procedentes del mundo musulmán ${ }^{7}$. Este período es conocido, en la periodización que Europa hace sobre sí misma, como Renacimiento (siglos XI y XIII d. C.).

Al constituir un solo pueblo con Roma desde el siglo II a. C., el pensamiento heleno impulsó el horizonte de sentido que le permitió a Roma imponerse y expandirse sobre Britania (Gran Bretaña e Irlanda del Norte en la actualidad), Galia (Francia), Hispania (España), Germania (Alemania), lo que en la actualidad son los Países Bajos, las costas del río Danubio (el cual nace en Alemania y atraviesa Austria, Hungría, Ucrania, Eslovaquia, Rumania, Moldavia, Bosnia, Croacia, Serbia, Bulgaria hasta desembocar en el Mar Negro, situado en las costas rumanas,

7 Dussel (2009) deja en evidencia que ya en el 947 d. C. existían molinos de agua y de viento en Seistan, ciudad cercana al río Indo; asimismo, en Basora, ciudad de Irak, se utilizó la corriente del Tigris para mover ruedas de molinos flotantes (p. 40). El mismo Dussel (2009) señala que "los molinos de viento de La Mancha, contra los que luchó el Quijote, vienen del mundo musulmán y no de los Países Bajos, evidentemente. Es decir, del horizonte cultural más desarrollado técnicamente" (p. 48). 
alcanzando los 2.888 kilómetros de expansión), Turquía y el Imperio Persa, Egipto, Marruecos, el Estrecho de Gibraltar, Túnez y Argelia.

A partir de la conversión de Constantino del paganismo al cristianismo la tradición cristiana, anteriormente dirigida por mujeres, ahora será dirigida sobre todo por hombres cuya preocupación será el dominio, control y poder sobre la tierra, ya no así la vida de la comunidad.

La tradición religiosa cristiana, que ahora es oficialmente religión del Imperio, se tensa entre el pecado y los pecados. Según el filósofo alemán-costarricense Franz Hinkelammert, Pablo Tarso, fundador de la Iglesia cristiana, "distingue entre el pecado y los pecados. Los pecados violan la ley. Sin embargo, el pecado se comete cumpliendo la ley. (...) Quien considera la justicia como resultado del cumplimiento de la ley, produce la injusticia. La ley, al ser considerada su cumplimiento como instrumento de la justicia, se transforma en su contrario: según palabras de Pablo, siendo ley de Dios se transforma en ley del pecado" (Hinkelammert, 2013, pp. 17-18). De esta forma, a partir del siglo VII d. C., san Ildefonso de Toledo (607-667), una de las principales figuras de la Iglesia visigoda en Hispania, invertía el sentido por el que los pueblos más diversos se encomendaban a sus vírgenes. A partir de ahora la maternidad virginal (Orlandis, 1981, 218-219. 305. En: Nebel, 2013, p. 41) se constituye en la principal doctrina a María que debe ser impulsada como fundamento divino de la humanización de Dios. Al igual que antes lo hiciera Grecia y Roma, el cristianismo se ha hecho de las condiciones discursivas para controlar y dominar en adelante el cuerpo de las mujeres.

La formalización de la filosofía y la ciencia se institucionaliza mediante la educación y el impulso a uno de sus principales centros para el dominio y control sobre el "Otro/Otra": la Universidad. A tan solo noventa y cinco años de la fundación de Constantinopla aparece este centro especializado en la enseñanza ${ }^{8}$.

Durante la Edad Media (siglos IV-XI), que es un periodo estrictamente europeo, y el período comprendido entre los años 1472 y 1821 en que se impuso la "Santa Inquisición", órgano represor de la Iglesia católica dirigida a perseguir, procesar y castigar actos de herejía y paganismo, cientos de miles de mujeres fueron muertas en la hoguera por

8 La Universidad, como centro especializado en la transmisión de un saber oficial, formalizado e institucionalizado cuenta con diez cátedras de lenguas latina y griega, retórica, filosofía, teología y derecho. 
poner a disposición comunitaria sus habilidades y saberes para hacer la vida posible. De esta forma, mujeres con conocimientos de botánica o biología, conocidas como brujas, fueron perseguidas y muertas según dictaba el orden eclesiástico. Un ejemplo de lo anterior es que solo en Perú se realizaron siete (7) autos de fe ejecutados por el Tribunal de la Inquisición de Lima entre 1569 y 1600; 15 autos de fe entre los años 1601 y 1700; 15 autos de fe entre los años 1701 y 1800; y tres (3) autos de fe entre los años 1801 y $1820^{9}$.

Las Jerarquías de Poder es el nombre con el cual se conocen las estructuras mentales y materiales cuyo sentido práctico con la vida cotidiana permiten establecer relaciones de privilegio e inferioridad con las y los "otros". Estas jerarquías se establecen en función de la cercanía o lejanía que se tenga respecto de las creencias, costumbres, tradiciones, lenguas, vestimentas, edad, sexo, sexualidad, etc., del pueblo, impuesto militar y colonialmente sobre los "Otros/Otras". Por lo anterior quisiera proponer el Quinto Momento Educativo como Momento Sexista-Cristiano-Patriarcal-Imperial.

\section{Conocimiento y sabiduría en la tradición mayo-azteca e inco-quechua}

Dado que las eticidades de este sistema interregional no acaba con su dimensión occidental, sino que producto de las movilizaciones humanas nuestra especie ya había poblado desde hacía mucho tiempo la redondez de la tierra (entre el 50.000 y el 35.000 a. C.), tanto la cultura mesoamericana (mayo-azteca), como la inco-quechua deben ser contempladas como parte de este sistema interregional. De esta forma, desde Alaska, que fue el último territorio conquistado por los europeos y el primer territorio por donde ingresa nuestra especie al continente americano, hasta la Tierra del Fuego el principio ético que permite la comprensión del mundo y el acercamiento a las preguntas pertenecientes al "núcleo problemático" es el de la dualidad y no la de lo "Uno" (Dussel, 2009, p. 30). De este modo "el 'Dos' de los tlamatinimme: el Ométeotl de los aztecas, la/el Alom-Qaholom (Madre-Padre) de los mayas, la/el Tocapo-Imaymana Viracocha de los amautas entre los incas,

9 En estos autos de fe murieron seres humanos encontrados culpables de herejes y paganos por parte de un tribunal destinado a hallar culpable todo aquello que no podía comprender y, por lo tanto, no toleraba. 
los 'gemelos' de todas las culturas, desde los Grandes Lagos o praderas de Norteamérica hasta los caribes y tupí-guaraníes o los alakaluf de la Patagonia autral" (Dussel, 2009, p. 30) se constituye en un horizonte de sentido distinto al que se impulsa, organiza y reproduce en la "Isla del Mundo" (Asimov, 2011).

En la cultura mayo-azteca coexisten varios tiempos en un mismo tiempo, de forma que existe un tiempo anterior a los dioses, a los que estos se deben, con diversos momentos contenidos en él hasta el nacimiento del Sol, en el que surge el ser humano. Cabe la posibilidad de que el ser humano pueda pasar de un tiempo a otro en el que los otros seres tienen cuerpo pero no materia "ligera", "invisible para nuestra sensibilidad humana de seres con materia 'pesada"' (Dussel, 2009, p. 30).

Su comprensión del mundo y propio sentido del desarrollo de las matemáticas los impulsa, al igual que los indios o babilónicos, a pensar en la noción matemática de la nada que es el todo: el cero (0), como ya había sido planteado. Esto permite complejizar la comprensión del mundo exterior a nuestra mismidad humana de forma que "la astrología racionaliza el futuro; la hermenéutica de los fenómenos (agüeros) descubre el sentido del presente; las teogonías (interpretación en base a observaciones astronómicas y al cielo agrícola) o 'protofilosofías' racionalizan las fuerzas cósmicas en relación con las instituciones sociales o políticas (un cosmopolitismo), todo en referencia a otros tiempo-espacios y a sus mutuos y continuos 'pasajes' hacia y desde el mundo humano" (Dussel, 2009, p. 30). Según la tradición teológica azteca, Quetzalcóatl habría ofrecido su sangre para que de ella surgieran las condiciones constitutivas de nuestra humanidad, tal como la conocemos en la actualidad. Según esta tradición ética, cada ser humano no estaría en deuda, como en los pueblos occidentales del sistema interregional indoeuropeo, sino que sería una elegida o un elegido y Quetzalcóatl lo que ha hecho es afirmar la vida sin intención de recibir nada a cambio. De esta forma "la justicia para con los miembros de la comunidad es un acto de exigida gratificación" (Dussel, 2009, p. 31).

Lo anterior permite identificar cómo en esta tradición cosmogónica lo distinto parte de otra racionalización que identifica las tensiones como parte del sentido del universo y de lo que es universal, mientras que la comprensión racionalizada y formalizada en la filosofía o la ciencia posterior a la Grecia clásica (siglos IV y III a. C.) es transferida a 
la eticidad cristiana donde lo uno y otro son lo mismo (Dios/diablo; Democracia/corrupción; Libertad/esclavitud; Paz/guerra; etc.).

La cultura inco-quechua, a diferencia del horizonte ético mayo-azteca, basa su comprensión del universo en tres imperativos formales: "Ama Lulla, Ama Kella, Ama Sua” (No mentirás, No dejarás de trabajar, No robarás).

No mentirás, en el conjunto de relaciones comunitarias que se tejen en el seno de la cultura inco-quechua, tiene un sentido profundo cuya pretensión es la sinceridad, la honestidad, la transparencia entre aquellas y aquellos que dan sentido e integran la vida en comunidad. No dejarás de trabajar tiene implicaciones universales, ya que todas las formas de vida, incluida la nuestra, son producto de la creación universal, entendida esta creación como una obligación ética de la humanidad hacia el trabajo que aleja la muerte, de manera que el trabajo humano es una responsabilidad cósmica. No robarás tiene un sentido mucho más amplio que en la concepción socializada, individualizada de la propiedad, que le asigna como suyo el producto a quien tiene la capacidad de compra mas no, necesariamente, a quien lo ha producido, de forma tal que la creación de un producto brinda el derecho de su uso o su consumo y la apropiación de lo que no se ha producido conlleva a un desequilibrio universal.

En este espacio, y quizá por su desconexión geográfica de lo que sucede en la "Isla del Mundo" (Asimov, 2011), las culturas mayo-azteca e inco-quechua tienen un horizonte de sentido distinto a la formalización racional de un saber basado en la Institucionalización Formal-Categorial de un Saber para el Dominio.

En la forma de proceder institucional/formal de la racionalidad helena el dominado es la diferencia, el "otro", el explotado, aquel quien no siendo el poder es, en última instancia, el fundamento del poder. Es el esclavo sin el cual no hay posibilidades materiales de organizar un sistema basado en la desigualdad pero, desde lo "Uno" que ha impuesto las condiciones materiales e intelectuales para la reproducción de sus privilegios, este esclavo es el "otro". De esta manera, en el tipo de proceder racional heleno, lo "Uno" y lo "Otro" son "lo Mismo" (Dussel, 2014c), mientras que la distinción, no lo diferente, sería aquello racional, mítico, teológico, científico que se encuentra fuera de su estructura lingüística y gramatical de la racionalidad, el poder. En la distinción cabría la alteridad, la diversidad que son las fuerzas constitutivas del 
Universo que permiten a los opuestos coexistir y no excluirse mutuamente como sucede en la racionalidad de "lo Mismo". Más que un momento, este tipo de "distinción" pertenece a un lugar "distinto", que sigue teniendo manifestaciones y expresiones cotidianas en el mundo andino-amazónico o en las montañas mesoamericanas, que ha sido posible de desarrollar previo a la imposición militar de Europa en lo que llegará a ser América a partir de 1492.

Este tipo de pensamiento "filosófico" se mantiene como acto de resistencia colonial que atraviesa las relaciones comunitarias en América Latina, aun cuando no seamos poblaciones autóctonas de esta tierra. Habiéndolo señalado como un lugar y no como un momento si quisiéramos pensar con ustedes el hecho de que ha sido la irrupción de "lo distinto" en la lógica educativa formal la que le ha dado posibilidades de pensar en la liberación y en la libertad, razón por la que quisiéramos atrevernos a nombrar este Sexto Momento Educativo como "Lo Distinto".

Según el filósofo argentino-mexicano Enrique Dussel (2009),

los egipcios efectuaron una primera 'racionalización' del mundo mítico por medio de una filosofía numérica (como la Kabbala después o los quechuas y aymaras en el Imperio inca): se piensa lo mítico-cotidiano desde 'números' significativos. Con Sócrates comienza otro tipo de racionalización, que pudiéramos llamar el de la lingüística-semántica del concepto, que será definitivamente formalizada en el Órganon de Aristóteles, por vez primera (p. 44).

Quedan expuestos, por ahora, seis momentos educativos como determinaciones que dan forma constitutiva a lo que es la Educación. Desde tradiciones éticas, culturales, técnicas, filosóficas o lingüísticas cada uno de ellos ha aportado, es un momento presente que suma tensión a la complejidad histórica de nuestro tiempo.

\section{Balance provisional}

Los saberes acumulados desde el primer sistema ético, el egipcio-mesopotámico (desde el IV milenio a. C) del que he dado cuenta en un artículo anterior, deben ser reconocidos como la materia prima sobre los que se yerguen los nuevos conocimientos logrados a través de la acumulación y sofisticación del saber. Esto les permitió a los pueblos 
indios, babilónicos, mayas, aztecas, incas y quechuas, aunque de forma desconectada, llegar a abstracciones racionales tales como el cero (0).

Si bien el saber acumulado nos ha permitido, como especie, lograr mayor sofisticación y desarrollo en el campo del conocimiento científico, y en tanto relación de dominio nos ha permitido dominar y controlar virus, gérmenes y bacterias con los que la humanidad ha alcanzado expectativas de vida como en ningún otro tiempo histórico, esto se ha hecho anulando, negando, invisibilizando los horizontes de sentido que nos han permitido, como especie, lograr tales avances. Un ejemplo de ello es cómo mientras que en el Sistema Interregional egipcio-mesopotámico lo diverso, la multiplicidad de dioses son razón y producto de la creación original, en el Sistema Interregional Indoeuropeo, surgido a partir del XX a. C., la creación original, la lluvia, la noche, el día se deben a un único horizonte de sentido del cual todo es resultado. Esto culminó por imponer la tradición hacia lo "Uno" e identificar la diversidad como un elemento negativo. Esto debe ser pensado con mucha seriedad en un tiempo que niega la vida misma de todo aquello que se muestra diferente.

El desarrollo de respuestas cada vez más ingeniosas cuyo nivel de sofisticación se fue complejizando con el pasar del tiempo, así como se fueron perfeccionando los saberes desarrollados con anterioridad, le permitió a nuestra especie formalizar un tipo de proceder metódico fundamentado en la imposición del Sujeto sobre el Objeto en la cual ante la aplicación de los mismos mecanismos se obtienen los mismos resultados. Esta forma de proceder les permitirá a los sectores oligarcas y aristócratas disponer de un método, Ciencia, para imponer sus lógicas sobre las otras existentes. A este momento en particular lo he propuesto como el Primer Momento Educativo: "Saber para el Dominio".

El Segundo Momento Educativo, sugerido como Institucionalización Formal/Categorial de un Saber para el Dominio, está relacionado con el desarrollo de las herramientas de medición-comparación para la comprensión de la realidad de la que la especie humana es tan solo parte. Este desarrollo categorial se impulsa situando al ser humano como el ser vivo alrededor del que deben girar todas las otras formas de vida existentes. Sin embargo, este desarrollo categorial será pensado para la apropiación excluyente del trabajo comunitario por parte de Hombres, Atenienses, Poseedores de Recursos Materiales, en condiciones de leer y escribir, reconocidos socialmente como mayores de 
edad, provenientes de la aristocracia y la oligarquía. Este es el momento fundante de la desigualdad que atraviesa el proyecto contenido en la Modernidad: Sexismo/Racismo/Clasismo.

El Tercer Momento Educativo identificado como Momento de Escolarización para la Reproducción de un Saber para el Dominio, permite identificar, aún en la actualidad, el horizonte de sentido que acompaña el proyecto educativo con que se dirigen las Academias y los Liceos. Desde que Aristóteles ejerce sobre ellos influencia, posterior al triunfo y expansión militar que ha adquirido Alejandro Magno en el siglo III a. C., el Sujeto y su preocupación seguirán siendo aristócratas y oligarcas, así como la reproducción de sus privilegios.

Lo anterior no tendrá posibilidad de extenderse en el tiempo, sino es a través de la expansión del proyecto civilizatorio romano. Este, de forma tautológica, se ve asimismo como el mejor proyecto humano posible y, cuenta para su expansión, con una indumentaria técnica, jurídica, legal y normativa que rige los designios del Imperio. Lo anterior nos impulsa a sugerir este Cuarto Momento Educativo como Institucionalización Formal de un Código Legal para el Control, la Reproducción del Poder y centralidad de Roma.

Dado que el Derecho Romano, institucionaliza y formaliza las condiciones de opresión preexistentes centradas en lo masculino, aún cuando también son mujeres romanas, en la actualidad alemanas o costarricenses, las que reproducen la verticalidad del poder, lo urbano, lo adulto, lo letrado, etc., y que esto fue solo posible a partir de la expansión del proyecto romano, que en el siglo IV d. C., se había hecho uno solo con la Iglesia cristiana, me he atrevido a nombrar un Quinto Momento Educativo al que propuse como Momento Sexista-Cristiano-Patriarcal-Imperial. Las implicaciones de este vínculo se extienden hasta la actualidad y condicionan las posibilidades para que mujeres, comunidades sexualmente diversas o que no están dispuestas a someterse a los designios legales, jurídicos y normativos del poder y control de Roma, tengan acceso a los bienes, servicios y al saber acumulado por nuestra humanidad a lo largo de los 130.000 años de existencia.

Dado que este tipo de racionalidad, de proceder, está centrado en el mundo circunscrito entre lo que en la actualidad es Asia, África y Europa, la "Isla del Mundo", la cual está pensada a partir de una dinámica dialéctica en la cual lo "uno" y lo "otro" son lo mismo, dejando en evidencia que lo "diferente" es parte constitutiva de lo "mismo", 
identificamos el tipo de racionalidad y ética de los pueblos autóctonos del Anáhuac, Abya-Yala y el Tawantinsuyu como lo "distinto", la diferencia de "lo diferente". Este giro gramatical les permite a estos pueblos operar fuera de la estructura lingüística de la racionalidad del poder de Roma. Más allá de un momento ya pasado, este tipo de "distinción" pertenece al presente en el que razonan, se manifiestan y expresan cotidianamente el mundo andino-amazónico o los pueblos que habitan las montañas mesoamericanas. Este tipo de pensamiento "filosófico" se mantiene como un acto de resistencia colonial al proyecto de dominio contenido en la racionalidad helena, romana y posteriormente occidental. De esta forma al Sexto Momento Educativo lo he denominado como "Lo Distinto".

Lo anterior nos permite identificar distintas determinaciones que constituyen en la actualidad lo educativo. Se trata de lograr identificar y trascender los momentos que tensan la producción y reproducción de la vida en un tiempo histórico que urge de la acumulación del saber y el conocimiento pasado. De ello quizá dependa nuestra propia existencia.

\section{Referencias}

Aristóteles. (2007). La política. México: Editorial Época.

Asimov, I. (2011). El cercano oriente. España: Alianza Editorial.

Baraona, M. y Herra, E. (2016). Danzando en la bruma junto al abismo. Las cuatro crisis y el futuro de la humanidad. Costa Rica: Editorial Arlekín.

Bautista, J. (2011). Crítica de la razón boliviana. Elementos para una crítica de la subjetividad del boliviano con conciencia colonial, moderna y latino-americana. Bolivia: Ediciones Rincón.

Dussel, E. (2009). Ética de la liberación en la edad de la globalización y de la exclusión. (Sexta edición). Madrid: Editorial Trotta, S.A.

Dussel, E. (2014a). Hacia un Marx desconocido: Un comentario de los manuscritos del 61-63. México: Siglo XXI Editores.

Dussel, E. (2014b). 16 tesis de economía política. Interpretación filosófica. (Segunda reimpresión). México: Siglo XXI Editores.

Dussel, E. (2014c). Para una ética de la liberación latinoamericana. (Primera edición). México: Siglo XXI Editores.

Dussel, E. (2015). Filosofias del sur. Descolonización y transmodernidad. México: Siglo XXI Editores. 
Echeverría, B. (2015). Ontología del lenguaje. Argentina: Editorial Granica.

Feyerabend, P. (1984). Diálogo sobre el método. En varios: Estructura $y$ desarrollo de la ciencia. España: Alianza Editorial.

García, R. (2000). El conocimiento en construcción. De las formulaciones de Jean Piaget a la teoría de los sistemas complejos. España: Gedisa Editorial.

García, R. (2013). Sistemas complejos. Conceptos, método y fundamentación epistémica de la investigación interdisciplinaria. España: Gedisa Editorial.

Herra, E. y Baraona, M. (2015a). El Estado como fundamento del proyecto Imperialista. (Ponencia) Coloquio Internacional Antiimperialismo Latinoamericano: historia, memoria, tradiciones, legados y prácticas contemporáneas. Centro de Investigaciones sobre América Latina y el Caribe y Vicerrectoría de Extensión Universidad Nacional, Costa Rica. 13-15 de abril de 2015.

Herra, E. y Baraona, M. (2015b). Hacia una epistemología radical de la descolonización. XXX Congreso Latinoamericano de Sociología. "Pueblos en Movimiento: Un diálogo en las Ciencias Sociales". Mesa 16: Pensamiento Latinoamericano: Hacia la Descolonización de las Ciencias Sociales. 29 de noviembre al 4 de diciembre de 2015. Costa Rica, 2015

Herra, E. y Navarro, L. (2014). Verde que te quiero verde. Incompatibilidades entre nuestra realidad y nuestra racionalidad. Práxis-revista de filosofía, 72, 25-40. doi: http://dxdoiorg/10.15359/praxis. $72.2 \mathrm{http} / / / \mathrm{dxdoiorg} / 10.15359 /$ praxis.72.2

Hinkelammert, F. (2013). La maldición que pesa sobre la ley. Las raíces del pensamiento crítico en Pablo de Tarso. Costa Rica: Editorial Arlekín.

Kusturica, E. (Productor y Director). (2004). La vida es un milagro. Serbia: Cameo Media S.L.

Menzies, G. (2015). 1421 El año que China descubrió el mundo. España: Grupo Editorial Random House.

Nebel, R. (2013). Santa María Tonantzin Virgen de Guadalupe: continuidad y transformación religiosa en México. (Cuarta reimpresión). México: Fondo de Cultura Económica. 
Pagden, A. (2014). Pueblos e imperios. Una breve historia de la migración, explotación y conquistas europeas, desde Grecia hasta hoy. España: Editorial Debate.

Quijano, A. (2000). Colonialidad del poder, eurocentrismo y América Latina. Recuperado de http://bibliotecavirtual.clacso.org.ar/ar/ libros/lander/quijano.rtf

Saavedra, M. (2013). Gnoseología y paradigmas epistemológicos. México: Ediciones Crisol. 